\title{
EDITORIAL
}

\section{Euthanasia: from ethical debate to clinical reality}

\author{
Thierry Berghmans* and Dominique Lossignol ${ }^{\#}$
}

$\mathbf{W}$ hile it may only be the third-leading neoplasm worldwide, lung cancer is the first cause of death by cancer in males and one of the first in females in industrialised countries. Overall, cure rate is only $10-15 \%$ and the majority of patients, most of whom are diagnosed at an advanced stage and will ultimately die from lung cancer progression or related complications. During the last few decades, palliative care has become a central element of the therapeutic approach to terminally ill cancer patients. Palliative care aims to improve quality of life and control symptoms but has no role in hastening death, although palliative care specialists can be involved in the end-of-life decision process when euthanasia or physician-assisted suicide are considered. The opinions of the cancer patient and their family, the treating physician, or both regarding their preferences in end-of-life decisions have been assessed in general studies not including a specific cancer type. Outside of religious or sociocultural particularities, suffering from pain or fatigue is a prominent factor associated with euthanasia requests and practice in cancer patients $[1,2]$.

Requests for euthanasia or assisted suicide are reported with higher frequency in poor-prognosis cancers, such as lung, pancreas, stomach, oesophagus, lip-mouth-throat or melanomas, in comparison with those having better life expectancy, such as as prostate or haematological tumours [3]. In this issue of the European Respiratory Journal, PARDON et al. [4] report the first study specifically dealing with euthanasia requests and practice in lung cancer patients. This prospective study was based on questionnaires sent to pulmonologists, oncologists and general practitioners immediately after the death of their patient. Among 115 deaths occurring during an 18-month period, 105 questionnaires were returned by the physicians, replies from specialists $(91 \%)$ being more common than from general practitioners (55\%).

After a long debate, Belgium became, along with the Netherlands and Luxembourg, one of the few places in the world where euthanasia is legal under certain conditions. The Belgian law of May 28, 2002 [5], published at the same time as the law on palliative care and the law relating to patients' rights, imposes several major obligations before access to euthanasia. They consist of: 1) giving to the patient all information about other therapeutic options and prognosis, particularly in relation to palliative care; 2) obtaining the opinion of a second or even a third doctor (in the case of unforeseeable short-term death); and

\footnotetext{
*Dept of Intensive Care and Emergency and Clinic of Thoracic Oncology, Institut Jules Bordet, and
} \#Dept of Supportive Care, Institut Jules Bordet, Université Libre de Bruxelles, Brussels, Belgium.

CORRESPONDENCE: T. Berghmans, Institut Jules Bordet, Rue Héger-Bordet 1, B1000-Bruxelles, Belgium. E-mail: Thierry.berghmans@bordet.be
3) in making sure that all persons designated by the patient have been met beforehand. The term euthanasia must be understood as being the act of ending, at their request, the life of an adult (or emancipated minor) who is capable of taking the decision, according to the legal definition. At the same time, the patient must suffer from a serious incurable condition, owing to an illness or an accident, and must experience constant and unbearable physical or psychological suffering, despite the best possible control that can be achieved with conventional treatment. This request must be repeated, with serenity, without external pressure. A "third party", in the case considered here a physician, will carry out the act, namely the euthanasia. It is important to stress that the physician can refuse to carry out euthanasia but can refer the patient to another one. Although of ethical concern, terminal or palliative sedation is not considered euthanasia from a legal point of view, despite the fact that in all situations, the patient will die following this medical decision.

The text of the Belgian law does not specify the practical medical methods to be used as the legislator believed that this was not his role. However, recommendations are available and have been published many times [6]. It is useful to specify that the legal text avoids the notion of medically assisted suicide and that the stages of the condition ("terminal phase", "palliative phase" and "end of life") are removed. Since its implementation, the Belgian Federal Control and Evaluation Committee (Review Committee) published the conclusions detailing the declarations of physicians who have carried out euthanasia. There is no indication given regarding the specific diagnosis, except for "cancer" or "neurological disease", in the annual reports provided by the Review Committee. Nevertheless, the majority of declared euthanasia concerned patients with progressing advanced cancer near the end of life [7]. It must be emphasised that physicians have to give enough information about the case and that an accurate diagnosis is required. This information is not communicated in the annual report but is available on individual request.

The present study [4] was performed in Flanders and, as such, included Dutch Belgian representatives. This is of importance when generalising the results of the survey to other countries, taking into account that the practice of euthanasia is officially restricted to countries where it is registered in the legal code, such as Belgium or the Netherlands. In 2011, 1,122 cases of euthanasia were reported in Belgium to the Review Committee [8]. A large difference is noted between French and Dutch euthanasia declarations, with 211 (17\%) and 911 (83\%) cases, respectively. Since the implementation of the Belgian law, the number of euthanasia declarations increased over time, from 17 per month in the first year to 38 per month in 2007 [7]. In the last $4 \mathrm{yrs}$, the number has doubled but still with the same 
discrepancy between the north and the south of the country. Besides the national statistics, it is interesting to note that observations in specific palliative and supportive care units show a different picture with no systematic progression of euthanasia, showing that the number of euthanasias is unpredictable but will never be zero [9].

The use of life-ending drugs in Flanders was reported to be $\sim 4 \%$ during the last decade [10], similar to what is observed in the Netherlands [11], with a $5-7 \%$ rate in cancer patients. PARDON et al. [4] emphasise that of a $14 \%$ rate of repeated requests for euthanasia, half were not performed, principally because the physician in charge of the patients during the terminal phase is not the one who received the request and was not aware of it. Conversely, a lower rate of requests for euthanasia, 2.1\%, was reported in palliative units in France [12]. In a Greek survey, only $40 \%$ of physicians and relatives will agree not to resuscitate terminally ill cancer patients in cases of cardiorespiratory arrest and only $20 \%$ of the physicians agree with euthanasia [13]. As we observe with Belgian statistics, societal or cultural aspects can impact end-of-life perceptions of patients or physicians. As already pointed out in a Korean survey, $50 \%$ of the patient and general population groups will approve euthanasia or assisted suicide while only $10 \%$ of oncologists will do so [14].

There are some other potential explanations for the differences facing euthanasia requests among countries. Physicians, general practitioners and specialists cannot be aware of the legal procedures (legal dispositions, declaration, etc.) and have limited experience regarding the euthanasia process when they are not frequently confronted with such situations. The attitude towards suffering patients can vary as, for example, euthanasia is less often reported in the south of Belgium where terminal sedation is considered an alternative option to euthanasia, but is not reported. Furthermore, lack of knowledge regarding end-oflife procedures or palliative care resources among specialists (i.e. oncologists) may lead to inappropriate decisions or inadequate management of advanced cancer patients. In lung cancer, a recent North American survey showed that physician referral to palliative care is negatively influenced by the perception that it can alarm patients and relatives while the belief in longer time to approach complex issues by the palliative care specialist is associated with more referral [15]. PARDON et al. [4] also underline a different perception of the euthanasia request by the specialist or the general practitioner. The perception of euthanasia and palliative care among the population is evolving and will certainly influence medical practice in the future, as suggested by the growing importance of advance directives or anticipated declaration among the Belgian population, 25,000 advance directives being officially reported to the authorities. This shows the importance attributed to end-of-life choice, including euthanasia, in the population, people anticipating the eventuality that they would no longer be able to express their wishes and choosing legal representative to decide in their place in this particularly sensitive setting.

The study by PARDON et al. [4] is the first disease-specific study on euthanasia and end-of-life decisions. The authors demonstrate that euthanasia is not an exception and is part of the end-of-life decision process in lung cancer in one of the few European countries, including Belgium and the Netherlands, where euthanasia is legally accepted under certain conditions. This study underlines the need for an integrative approach of specialists and general practitioners in charge of these patients not only at diagnosis and during active treatment but also when palliative care and symptom control are the only way of helping the patient.

\section{STATEMENT OF INTEREST}

None declared.

\section{REFERENCES}

1 Georges JJ, Onwuteaka-Philipsen BD, van der Wal G, et al. Differences between terminally ill cancer patients who died after euthanasia had been performed and terminally ill cancer patients who did not request euthanasia. Palliat Med 2005; 19: 578-586.

2 Maessen M, Veldink JH, van den Berg LH, et al. Requests for euthanasia: origin of suffering in ALS, heart failure, and cancer patients. J Neurol 2010; 257: 1192-1198.

3 Abarshi E, Onwuteaka-Philipsen BD, van der Wal G. Euthanasia requests and cancer types in the Netherlands: is there a relationship? Health Policy 2009; 89: 168-173.

4 Pardon K, Deschepper R, Vander Stichele R, et al. Expressed wishes and incidence of euthanasia in advanced lung cancer patients. Eur Respir J 2012; 40: 949-956.

5 Sénat. Belgique [Belgium]. www.senat.fr/lc/lc109/lc1091.html

6 Lossignol D. Euthanasia: medication and medical procedures. Rev Med Brux 2008; 29: 435-440.

7 Figa B. Bilan de l'euthanasie en Belgique 2002-2007 [Evaluation of euthanasia in Belgium 2002-2007]. Rev Med Brux 2008; 29: 419-421.

8 Federal Public Service. Euthanasia. http://health.belgium.be/ eportal/Healthcare/Consultativebodies/Commissions/Euthanasia/ Publications/index.htm Date last accessed: July 31, 2012.

9 Lossignol D, Libert I, Michel B, et al. End-of-life decision, euthanasia, in a Belgian supportive care unit. Support Care Cancer 2011; 19: Suppl. 2, S67-S370.

10 Bilsen J, Cohen J, Chambaere K, et al. Medical end-of-life practices under the euthanasia law in Belgium. N Engl J Med 2009; 361: 1119-1121.

11 van der Heide A, Onwuteaka-Philipsen BD, Rurup ML, et al. Endof-life practices in the Netherlands under the Euthanasia Act. N Engl J Med 2007; 356: 1957-1965.

12 Comby MC, Filbet M. The demand for euthanasia in palliative care units: a prospective study in seven units of the "Rhône-Alpes" region. Palliat Med 2005; 19: 587-593.

13 Parpa E, Mystakidou K, Tsilika E, et al. Attitudes of health care professionals, relatives of advanced cancer patients and public towards euthanasia and physician assisted suicide. Health Policy 2010; 97: 160-165.

14 Yun $\mathrm{YH}, \mathrm{Han} \mathrm{KH}$, Park S, et al. Attitudes of cancer patients, family caregivers, oncologists and members of the general public toward critical interventions at the end of life of terminally ill patients. CMAJ 2011; 183: E673-E679.

15 Smith CB, Nelson JE, Berman AR, et al. Lung cancer physicians' referral practices for palliative care consultation. Ann Oncol 2012; 23: 382-387. 